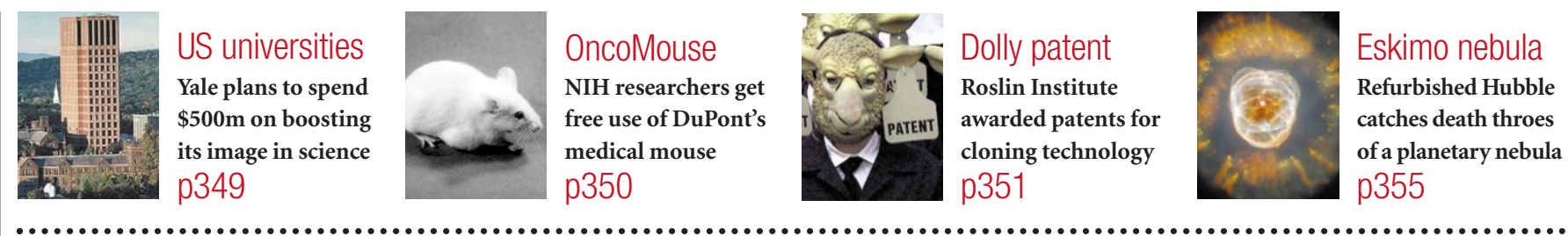

\title{
All parties keen to press on with Europe-based science website
}

Paris

Plans to launch a Europe-based global website for the scientific literature, E-Biosci, were unanimously endorsed by research organizations, commercial publishers and the European Commission in Heidelberg last week.

There was less agreement on what form the proposed site should take, however. There was a strong feeling that it should cooperate rather than compete with the similar US initiative, PubMed Central, that is being led by the National Institutes of Health and is due to be launched next week (http:// www.pubmedcentral.nih.gov).

Major publishing houses at the meeting included Elsevier Science, Springer, Blackwell and the Nature Publishing Group. "The presence of the publishers was critical," says Tony Mayer, an official at the European Science Foundation in Strasbourg.

The meeting also confirmed the differing US and European approaches to the goal of a single full-text searchable gateway for the scientific literature. PubMed Central (PMC) has made 'barrier-free access' its raison d'être and has invited commercial publishers and learned societies to deposit papers on its site free of charge - which one observer likens to "inviting turkeys to a Christmas dinner".

Several journals, including the Proceedings of the National Academy of Sciences, have signed up, and more are likely to do so (see over). But most commercial publishers have shunned the initiative. In contrast, the organizers of E-Biosci seem ready to compromise on barrier-free access, at least in the immediate future.

One proposal floated at last week's meeting by Stefan von Holtzbrinck, managing director of the Nature Publishing Group, was that publishers might cooperate with EBiosci to establish a single full-text searchable site (see Nature 402, 115; 1999).

The emerging picture is that E-Biosci would hold abstracts covering a range of disciplines, linked to the full text of the articles. Brigitte Volk-Zeiher, an official at Germany's Deutsche Forschungsgemeinschaft, wants a site "for all abstracts in science that would be much more complete than PubMed".

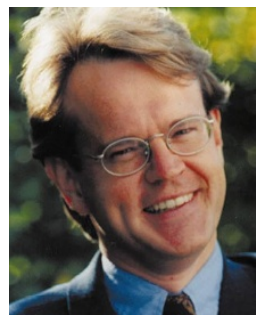

Such a site would be a valuable archive, says Frank Gannon, executive director of the European Molecular Biology Organization $(\mathrm{EMBO})$ and the driving force behind EBiosci. "But whether it von Holtzbrinck: "A would be free would be global venture." a 'per publisher' decision," he adds.

This scheme would fall short of the ideal of a "single, searchable, current, complete and free site," says Gannon, but it would let EBiosci quickly acquire a critical mass of current papers and allow full-text searching across a swathe of journals. Ways to achieve freer access could be negotiated with time.

"We are talking about a portal for all life sciences, a global repository headquartered in Europe," says Gannon. "The reality is: will anything happen if you do not reach a compromise with the publishers?"

"One way to potentially break the stalemate between the publishers and these initiatives is to take the positive points and begin in small steps," says von Holtzbrinck. "The 'E' in E-Biosci stands for electronic, not Europe," he adds. "It is a global venture."

Some feel that Gannon has gone too far in his efforts to meet publishers' needs. The cost of a freely accessible server "would only be a fraction of what is now disappearing into the pockets of publishers' shareholders," says Raf Dekeyser, chieflibrarian at Leuven University in Belgium. He criticizes "the influence of the publishers and some scientific societies who are afraid to lose their source of income".

"In my opinion, the big players like Elsevier will never voluntarily commit suicide by

\section{Quality, not quantity, for UK PhDs?}

\section{London}

Annual stipends for British research students should increase by more than a third - even if it means fewer studentships - according to a report published last week.

The report was produced for the UK Life Sciences Committee, an umbrella organization representing a range of biological and biomedical societies. It calls for better quality and support of research studentships, rather than maximizing the number of students at the lowest price.

"Filling the places is not the same as getting the best students into science," says Brian Follett, vice-chancellor of the University of Warwick and chair of the group that wrote the report. The report says that all PhD students funded by the UK research councils should receive a tax-free stipend of at least $\mathfrak{E 9 , 0 0 0}(\$ 14,900)$. The average is currently about $\mathfrak{E 6 , 6 2 0}$.

Follett says he hopes the government will provide fresh leadership and thinking on $\mathrm{PhD}$ funding and recruitment — an area that has been unchanged for at least 40 years. The timing of the report is appropriate, he says, given that the government is in the middle of a public-spending review.

Policy changes mean that new graduates carry debts of around $\mathfrak{E 1 0 , 0 0 0}$. The $\mathrm{PhD}$ system must change to reflect this, says Follett, because the average research student would not clear such debts until 15 years after graduation. This would deter people from poorer backgrounds from entering research.

Follett acknowledges that not all academics will be pleased to see a reduction in the numbers of PhD students. But, he says, "we need a culture change, away from a policy of maximizing numbers towards a much greater emphasis on the student, their training and their future."

He says that he is optimistic that government officials will take the report on board. It is now with the directorgeneral of the research councils and the chief executives.

Natasha Loder 
- giving their content away for free," says Dekeyser. "We have to force them to come down to reasonable prices by first creating an alternative electronic distribution channel, with the help of the refereeing scientific societies, in order to guarantee quality."

E-Biosci has been weakened by publisher involvement, he says. "In spite of the enthusiasm, the final E-Biosci proposal is very weak." Others point out, however, that initiatives such as PMC and E-Biosci are giving publishers sleepless nights, and the fact that Elsevier - notorious for its 40 per cent plus profit margins - attended last week's meeting is significant.

The days of fat profit margins are over, says one publisher, arguing that E-Biosci allows publishers to evolve without driving them to extinction. He predicts that publishers will settle for 10 per cent margins, while seeking new routes of income, other than primary publishing, through on-line opportunities.

The European Bioinformatics Institute (EBI) presented a bid to host E-Biosci. But while participants seemed enthusiastic that EBI should play a key role, many felt that a decentralized network was preferable, with EBI as the central node in a European network and other nodes in the member states.

One official from the European Commission says that the meeting's main legacy may be a pan-European information-technology infrastructure, linking existing electronic libraries such as DIMDI in Germany and France's INIST.

DIMDI already loads databases from the US National Library of Medicine as well as European ones, points out Dieter Kaiser, heads of its System Development Group.

All the representatives of member states' research councils contacted by Nature said that they strongly backed E-Biosci, but could not make financial commitments until the proposals had been fully discussed at home.

The inherent delays in reaching agreement among European member states could be the biggest obstacle to making speedy progress, warn several of the participants, who are concerned that the project risks getting bogged down in endless discussions.

Although little money is on the table, EBiosci's estimated annual budget of 3 million euros (US\$3 million) is small, says Marja Makarow, who represented the Academy of Finland and the country's Medical Research Council at the meeting. E-Biosci could allow national funding agencies to make economies in library costs, Makarow adds.

A recurrent theme was whether public money might be better spent on transferring resources from conventional libraries to a global archive. Librarians and universities urgently need to be brought into discussions of E-Biosci, say many participants.

The meeting agreed to submit a proposal to the European Commission for funding,

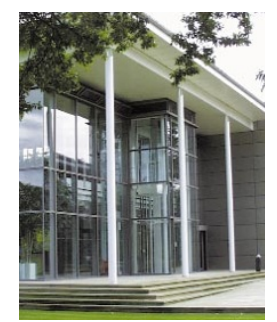

EBI: candidate for a central node. but felt that money was needed immediately to launch the initiative in the coming months. It agreed to set up a task force to resolve technical requirements for $\mathrm{E}$ Biosci, while the publishers will discuss their joint initiative further.

The European Molecular Biology Council, which represents member states, will seek to coordinate funding for E-Biosci through its member states, with input from the European Science Foundation, which covers a wider range of disciplines. But Carthage Smith, head of international relations at Britain's Medical Research Council, says it is "far more important for Europe to get this right than to do it quickly".

The mood of the meeting was that a European archive was essential to avoid a US monopoly on a global scientific archive. But it was also unanimous that E-Biosci should collaborate, rather than compete, with PubMed Central. "We need coordination with the US, but coordination of equals," says Glauco Tocchini, secretary general of the European Molecular Biology Council.

"Anything that Europe does must be coordinated with the United States; if we end up in a competitive situation over the scientific literature then it is to no-one's advantage," says Smith. "Europe can go in with a different starting position but all the content must be shared. It must be a global resource." National Council for Biotechnology Information, which operates the PubMed and GenBank databases, says he is "hopeful that we will set up a smooth collaboration" and adds: "in any case, we need advice and input from European scientists and administrators for PubMed Central".

PubMed Central will publish refereed material from existing journals or new organizations such as Current Science's BioMed Central; it will also have a server for unrefereed e-prints from academic institutions. Most of the participants at the meeting insisted on the need for peerreview, and the original E-Biosci proposal for including both peer-reviewed material and preprints was widely contested.

In particular, they rejected an EBI proposal that the archive should contain articles that had simply been checked for accuracy. Smith describes this concept as "dangerous, pseudo quasi review," adding: "We have enough trouble reviewing the reports for the best journals. Scientists are not going to review all this stuff."

"A repository for $\mathrm{PhD}$ theses within $\mathrm{E}$ BioSci should be established," adds Henning Beck-Nielsen, chairman of the Danish Medical Research Council. "This will also promote a harmonization on the level of quality for PhD degrees." Declan Butler
David Lipman, director of the US

Yes, no and maybe: where they stand on PubMed Central, the US biosciences online archive

Proceedings of the National Content available four weeks after print publication, for an experimental period of one Academy of Sciences year; contingent on non-peer-reviewed material being kept off PMC. No third-party use.

Molecular Biology $\quad$ Full contents available next year on an experimental basis,

of the Cell two months after publication. Will also provide back issues.

Canadian Medical $\quad$ Agreed to join.

Association Journal

Frontiers in Bioscience Agreed to join.

Current Science Group $\quad$ Five journals available initially; also providing peer-review services for PMC (see Nature 402, 110; 1999)

British Medical Journal $\quad$ Content available at time of publication.

Journal of Cell Biology $\quad$ May post 1-2-year-old issues, contingent on peer-reviewed journals not being mixed with an unreviewed preprint server. Also interested in "independent non-profit and commercial solutions to the linking problem".

American $\quad$ Will offer content free 12 months after publication; will not release before without a Physiological Society viable financial model.

American Society $\quad$ Supports concept. Makes content freely available via HighWire after one year. Does not of Microbiology $\quad$ intend to participate in PubMed Central until the requirement for hosting on the NIH server is dropped.

EMBO Journal Undecided. May join as part of a joint venture between PMC and E-Biosci (see above) Genes and Development $\quad$ Believes that "further study is needed" and many questions still need to be answered. Journal of Clinical $\quad$ Provides free access via HighWire. "A three-year 'experiment' with free access has Investigation been associated with a 10 per cent drop in overall subscriptions." Willing to consider full text access via links to HighWire; moving to PMC "contingent on the level and quality of service being at least as good as HighWire."

Journal of Neuroscience In discussions; undecided.

Nature $\quad$ Agreed that something like PMC could help enhance Nature's ability to serve the research community, but sees significant unanswered questions. In discussion with PMC and E-Biosci.

Nucleic Acids Research $\quad$ Still negotiating, but expects to join PMC early this year.

Oxford University Press (OUP) "In negotiation with the National Council for Biotechnology Information about the possibility of OUP submitting some journals to PubMed Central." Wants "same kind of usage data that we currently get from the HighWire system".

Science "So long as the $\mathrm{NIH}$ insists that it must have our meta content for both searching and dissemination, we will stand by our current decision not to participate." 